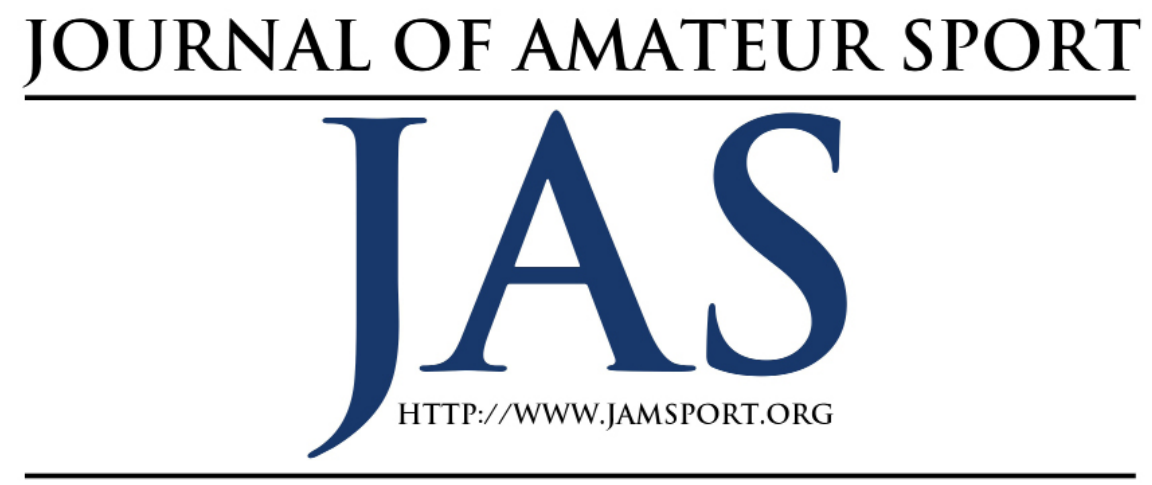

\title{
Attracting Spectators to Youth Sport Events: The Case of the International Children's Games
}

\author{
Ryan Snelgrove ${ }^{1}$ \\ Marijke Taks ${ }^{2}$ \\ Daniel Wigfield ${ }^{1}$
}

Laura Wood ${ }^{1}$

\author{
Luke Potwarka ${ }^{1}$
}

\section{${ }^{1}$ University of Waterloo \\ ${ }^{2}$ University of Ottawa}

\begin{abstract}
Small scale events are plentiful, but struggle to attract spectators more so than mega events. Highly identified fans of the sport on display are an obvious target market for small events in addition to individuals who are personally affiliated with athletes competing in the event. However, these potential spectators may be hard to impress given their expertise and event experience. The purpose of this study was to determine whether perceptions of value of a youth sport event were related to a spectator's sport identity, their personal affiliation with an athlete, and how their assessment of the event's uniqueness affects these relationships. Data were collected from spectators $(n=714)$ at the 2013 International Children's Games using a questionnaire that contained measures of sport identity, perceived uniqueness of event elements, perceived value, and demographic information. A measurement model was assessed using confirmatory factor analysis, and tested using structural equation modeling. Results provided support for an indirect only mediated model, such that spectators who highly identified with being a sports fan perceived the event as being valuable when they also viewed the event as unique. Having a personal affiliation to an athlete was not related to perceptions of uniqueness or value. Thus, purposefully selecting and designing unique events and promoting the unique attributes of the event could increase an event's appeal to spectators who highly identify with the sport.
\end{abstract}


$\mathrm{M}$ any communities frequently host non-mega sport events, which hold the potential to create positive impacts for them (e.g., tourism, economic, entertainment, pride). Stated simply, the distinction between non-mega and mega sporting events is one of size. Specifically, mega sporting events (e.g., Olympic Games) consist of significantly greater visitor attractiveness, mediated reach (i.e., media attention), costs, and transformative impact (i.e., infrastructure upgrades in the host location; Müller, 2015). Conversely, research has identified that smaller scale events can lead to positive impacts such as economic benefits to the host community, in a way that mega events are not able to deliver (Higham, 1999). These community events have been found to provide entertainment, which is often free for locals (e.g., Daniels \& Norman, 2003), potential for positive economic benefits if leveraged correctly (e.g., Agha \& Taks, 2015; Daniels \& Norman, 2003; O’Brien \& Chalip, 2008), an enhancement of destination image and intentions to return (e.g., Kaplanidou \& Vogt, 2007), provide opportunities for local tourism development (e.g., Gibson, Kaplanidou \& Kang, 2012), and create positive social impacts such as the development of closer social networks and connectedness in communities (e.g., Taks, 2013; Taks, Chalip \& Green, 2015), among others. As noted by Walo, Bull and Breen (1996), smaller events can operate within the resource capacity of the community, resulting in low opportunity costs and significant benefits for the commu- nity. As a result of the espoused benefits, communities have started to become aware of the potential that coincides with hosting smaller scale sport events.

In many cases, non-mega sport events have the potential to attract spectators from the local community as well as visitors. For good reason, sport tourism research focuses on factors that attract visitors to sport events. However, the attraction of local residents also matters insofar as sport events can create positive social impact for the host community (Chalip, 2006). Furthermore, creating events that also appeal to local residents can help provide support for the use of public funding to subsidize events (Rui, Correia, Santos, Ross, \& Yoshida 2017). Thus, event organizers and city officials tasked with the selection of sport events that capture the interest of spectators need to understand elements of an event that all spectators perceive to be valuable.

A significant amount of research has identified motivations behind sport event attendance (James \& Ross, 2004; Kim \& Trail, 2010). Typically, these studies have focused on internal and external factors related to entertainment, escape, social interaction, price, and promotions (Trail, Fink, \& Anderson, 2003; Trail \& James, 2001; Wann, 1995). However, some scholars have noted that much of the research on spectator motivation has explained little variance in key outcomes such as perceived value (Funk, Filo, Beaton, \& Pritchard, 2009; Kim, Trail, \& Magnusen, 2013). Perceived value (i.e., the extent to which people perceive benefits to 
outweigh the costs of consumption) is important because it has been long been identified as an effective means of generating customer loyalty and delighted customers (Lee, Lee, \& Feick, 2001; Oliver, 1999). Previous research has suggested that highly identified spectators (i.e., the extent to which spectators define themselves by the same attributes the event does) are more likely to see value in an event (Kwon, Trail, \& James, 2007).

However, other potential antecedents and mechanisms that might be related to the perceived value of event attendees have received considerably less attention from sport researchers. Similar to the positive relationships between event/ team identification and perceived value (Kwak \& Kang, 2009; Kwon et al., 2007), the connection to participants may affect the perceived value of an event (Kaplanidou \& Gibson, 2012a). These relationships might, however, be more complex and involve mechanisms and constructs previously unexplored. In particular, we explored the possibility that perceived uniqueness of an event might mediate the relationship between identification and perceived value, as well as between personal affiliation and perceived value. In other words, highly identified spectators, and/or spectators with a strong personal affiliation, may need to perceive the event as being unique in some way in order to be "impressed" or perceive value in attending the event.

Recently, scholars have suggested that perceived uniqueness of event elements may play a crucial role in attracting spec- tators (Yoshida, James \& Cronin, 2013). Components that contribute to event experience include athletic performance (e.g., featured sports, skill level, participant groups), the physical space and atmosphere, ease of accessibility (e.g., venue, geographic location), and opportunities to socialize (Yoshida et al., 2013). While these elements are generic in nature, their tailored version makes each event unique. There is a limited understanding of the uniqueness of these elements in the context of non-mega sport events and how these elements relate to spectators' identification with an event and their perceptions of value. We explored this idea in the context of a youth sport event, the International Children's Games. Specifically, the purpose of this study is to determine whether perceptions of value were related to a person's sport identity, their connection to an athlete, and how their assessment of an event's uniqueness affects these relationships.

\section{Literature Review}

\section{Identification with the sport and}

\section{perceived value of event attendance}

At an event, spectators or participants can be distinguished by their relative interest in and personal connection to the sport (Snelgrove, Taks, Chalip, \& Green, 2008; Wood, Snelgrove, \& Danylchuk, 2010) and/or their affiliation to the athletes, particularly in the case of youth sport events (Kaplanidou \& Gibson, 2012a). For example, some people may personally define themselves, in part, by being a fan or participant of a particu- 
lar activity, organize their lives around the activity, purchase related goods and services, and establish relationships with similar others (Green, 2001; Shipway \& Jones, 2007). Event attendance is one key way for highly identified participants to celebrate this aspect of their identities (Green \& Chalip, 1998). Highly identified individuals are also more likely to have a longer history of being involved with the event or similar events (Snelgrove \& Wood, 2010). Therefore, spectators who strongly identity with a sport may be more likely to view the event as valuable as it enables them to express and celebrate their identity.

People who identify with a sport see more value in attending an event if the event is important (e.g., in terms of competition standings), has a challenging adversary, is infrequent and/or is of high quality (e.g., Mullin, Hardy and Sutton, 2014). In the same vain, it is reasonable to assume that, in the absence of these features (i.e., importance, quality, challenging adversary), people who identify with a sport event may still perceive value in their attendance if the event is perceived as being unique. Although this mediating role of perceived uniqueness has yet to be explored in sport event consumer contexts, there is research in the product-based consumer behavior literature that serves to justify and explain our contention in this regard.

Henard and Dacin (2010), for example, found that consumers who were highly involved with a product required continued innovation from the company to remain loyal and continue to perceive value. The authors explained the mediating role of their "innovation" construct by arguing that heightened perceptions of product innovation via the involvement construct led to heightened levels of excitement toward and loyalty to the firm. Thus, it is reasonable to suspect that perceived uniqueness of an event may play a similar role the context of perceived value of events. Highly identified spectators may need to experience a sense of excitement derived from novel event stimuli in order to perceive value in the experience. By extending the findings of Henard and Dacin (2010), we argue events that fail to be unique or innovative may quickly lose appeal to highly identified spectators. We explore the construct of unique elements of an event below.

\section{Personal affiliation to athletes and perceived value of event attendance}

The positive relationships between event/team identification and perceived value has been well established in the literature (Kwak \& Kang, 2009; Kwon et al., 2007). In the same vain, the personal affiliation of spectators to participants may affect perceived value through feelings of emotional attachment. Particularly, this can be the case for youth sport events, where community and family members related to the athletes experience a range of emotions while watching "their" athletes perform (Kaplanidou \& Gibson, 2012a). This group of spectators may come from the local community if events are held within their home city or 
they may be visitors spending time in the destination for the duration of the event (Kaplanidou \& Gibson, 2012b; Wiersma \& Fifer, 2008). Dorsch, Smith, and McDonough (2009) found that affective states of parent spectators were characterized by pride, enjoyment, and anxiety related to performance outcomes and vicarious attachment.

Kaplanidou and Gibson (2012a) examined the impact of attitudes, social norms, and perceptions of event image on traveling parents' intentions to keep attending youth sport events. They suggested that, although parents may have limited options in event choice, they still critically evaluate the experience and form an image of the event, develop attitudes, and have some latitude in future event attendance. Results of Kaplanidou and Gibson's (2012a) study indicated that overall event image was related to attitudes toward the event, social norms, and future intentions.

Research on event image and event experience focuses primarily on service quality to the consumers (e.g., Ko, Zhang, Cattani \& Pastore, 2011), the level of excellence by which the events are organized, destination amenities, and emotional stimulation (e.g., Kaplanidou \& Gibson, 2010; Wigfield \& Chard, 2018); but ignores the role played by unique features of events. Understanding the perceived uniqueness of an event may explain some of the variation in perceptions of the event's worth (i.e., perceived value) as parents seek to differentiate numerous events they attend from each other and fulfill some quest for novelty. As noted in Wigfield and Chard's (2018) analysis of the experiences of parents attending youth hockey tournaments, the perception of value that a parent has of an event is a significant determining factor on intentions to return or attend similarly operated events. Thus, although those related to an athlete may be more likely to see value in a youth event because of a stronger emotional connection than someone not related to an athlete, we predict this relationship may be more likely when perceptions of uniqueness are high.

\section{Uniqueness of Event Elements}

A number of elements work together to create the experience of an event. Although consumers often interact with an organization before, during, and after a service experience, this study focuses on event design because it allows for the most detailed comparison between sport events (e.g., Kelley \& Turley, 2001). Various classifications of event elements have emerged in the literature. In a general service context, Pullman and Gross (2004) classified the components of a service encounter to be physical or relational. Thus, they identified the importance of creating opportunities for people to interact with others and an atmosphere that promotes a desired message or theme. However, one limitation of Pullman and Gross's classification scheme is that it lacks an athletic performance component for it to be transferable to a sport event context. Some 
researchers have distinguished a sport event service encounter in terms of technical aspects (e.g., sport performance), functional aspects (e.g., facilities, event staff), and relational aspects (e.g., fan-tofan, business-to-fan) (Brady \& Cronin, 2001; Kelley \& Turley, 2001; Shonk \& Chelladurai, 2008; Yoshida \& James, 2011). Yoshida et al.'s (2013) research further refines these previous classifications by delineating functional aspects into bow the sport offering is delivered and where the facility is located. Specifically, Yoshida et al. (2013) classified event elements in four ways: event offerings, aesthetics of the event, how services are accessed by consumers, and relationships found within the event. However, little is known about how consumers use these elements as points of distinction with other events. For the purpose of this study, event offering, aesthetics, access, and relationships are employed as factors to measure perceived uniqueness.

A sport event offers an opportunity to participate in or watch an athletic performance. These athletic performances can be exhibitions of skill and thrilling (Yoshida et al., 2013). Spectators watching sport may be impressed by the execution of a particularly difficult play, an athlete's ability to execute a play under pressure or in a key moment, or the sheer dominance of an athlete over the rest of the competition. In each case, the point of comparison for the spectator may be the particular context and related expectations. That is, spectators may still be impressed by a young athlete's per- formance even though it may not be as impressive as an older professional athlete's performance. Conceivably, a spectator may have a deeper appreciation for athletic performances when they possess a fairly good understanding of the sport being played (e.g., knowing how difficult it was to execute a particular play or shot) as compared with a casual or novice fan. Research in the elite sport context has demonstrated that skill and star athletes are one of the motivating factors that drive spectators' interest in watching an event (Mahony, Nakazawa, Funk, James, \& Gladden, 2002; Trail, Robinson, Dick, \& Gillentine, 2003). However, much less attention has been paid to spectators' perceptions of non-elite athletes. The second component of the offering is the thrill of the performance that comes from the unpredictability of sport and the drama of the moment (Yoshida et al., 2013). The thrill of an event can be influenced by a promotion of the athletic performance (e.g., star players, rivalries) or attempting to create a balanced competition so that the outcome of the competition is uncertain until the end (Yoshida \& James, 2010; Yoshida et al., 2013).

In addition to the physical performance of the athletes, spectators can also experience and be excited by the physical space around them. The beauty of nearby mountains at a road race, the history and tradition of Boston's Fenway Park, or modern aesthetics of a new football stadium all have characteristics that appeal to consumers' senses and potentially make them unique from other 
settings. Aesthetically appealing settings contain elements that are visually pleasing to consumers (Yoshida et al., 2013). For some consumers, they may be motivated in part to attend an event because of the unique geographical location of the event (Snelgrove \& Wood, 2010). In addition to the geographical location of an event or venue, consumers' perceptions about the event can be influenced by facility cleanliness, layout, colors, and electronic displays (Wakefield \& Blodget, 1996). Importantly, consumers are also positively influenced by consistent theming throughout the event area that delivers a message about the event and creates excitement (Berry, Shankar, Parish, Cadwallader, \& Dotzel, 2006; Berridge, 2012; Pullman \& Gross, 2004). Although event organizers cannot directly control the outcome of the sport performance, they can influence spectator perceptions based on aesthetics. Consequently, Yoshida and James (2010) emphasized the importance of promoting event atmosphere in combination with the core product (e.g., athlete performance, rivalries, history of teams or competitors).

Not only are aesthetics and related theming an important element of the consumer experience, so is how consumers access the location or service. The sport event experience can be delivered to a consumer in many ways, such as physical attendance at the event, consumption via traditional media (e.g., television, radio), or consumption via social media (e.g., twitter) (Berry et al., 2006). With respect to physically attend- ing the event, a consumer encounters a number of elements on the way to a venue, such as how to travel to the event, parking availability, and the possibility of traffic congestion (Kruger \& Saayman, 2012). For some consumers, perceived accessibility of a venue, before or after an event, is a factor in whether they will attend an event (Pritchard, Funk, \& Alexandris, 2009). The manner in which access to a service is conceptualized can vary depending on context and dependence on service employees or self-service technology (Yoshida et al., 2013). As highlighted in a study of marathon runners' experiences, Kruger and Saayman (2012) found that positive impressions about access to the venue was a factor in participants' positive memories of the event. Thus, event organizers are encouraged to create unique ways of accessing venues in order to enhance the consumer experience (Yoshida et al., 2013).

Once a spectator is at an event, relational experiences are also an important part of the event experience for many consumers (Nordvall, Pettersson, Svensson, \& Brown, 2014). This element focuses on spectators' feelings of oneness or connection with others in the setting (Pullman \& Gross, 2004). Relationships can occur between the consumer and service provider, and between consumers. Consumer to service provider relationships are typically created through past consumption (Pullman \& Gross, 2004) and may be facilitated by loyalty programs (Yoshida et al., 2013). Consumer to consumer bonds can be cre- 
ated as the event unfolds, as consumers feel connected to others. A significant amount of research has demonstrated the existence of consumer-to-consumer relationships in brand communities (McAlexander, Schouten, \& Koenig, 2002; Muniz \& O'Guinn, 2001) and at events (Green, 2001; Green \& Chalip, 1998; Hassay \& Peloza, 2009; Nordvall et al., 2014; Shipway \& Jones, 2007; Yoshida et al., 2013). Given the importance of consumer-to-consumer relationships at events, researchers have advocated for the purposeful design of events in a way that allows for and encourages interactions (Green, 2001; Nordvall et al., 2014).

In the context of one-time sport events that are hosted by different cities or countries annually, many consumers will likely have very little past experience with the event and particularly the local event organizing committee, making the consumer to service provider relationship less significant. Although research has identified the existence and importance of spectator communities at events to the overall consumer experience, little is known about how important relationships are to the way consumers place value on non-mega sport events.

\section{Perceived Value}

Zeithamal (1988) suggested that perceived value is a "consumer's overall assessment of the utility of a product (or service) based on perceptions of what is received and what is given" (p. 14). Thus, an individual would weigh the cost versus the perceived benefit in a specific business transaction to determine the perceived value of the referent product. In particular, this study focuses on understanding the elements of a youth sport event that make them unique and valuable to spectators. Perceived value has been conceptualized as a multi-dimensional construct. Specifically, Sweeney and Soutar (2001) conceptualized value as having four components: price value (i.e., utility derived in light of the costs of product), performance quality (i.e., perceived quality of performance of product), emotional value (i.e., the feelings a product generates), and social value (i.e., an enhancement of social image through consumption of the product).

As noted, the four event elements discussed have been shown to play a role in shaping positive event experiences for attendees (Shonk \& Chelladurai, 2008; Wakefield \& Blodget, 1996). To date, limited research on sport events has considered relationship between perceived uniqueness and perceptions of value (Yoshida \& James, 2010). As the number of sport events continue to grow in many communities, it is becoming increasingly important for organizers to improve perceptions of value among spectators to remain competitive and build loyal relationships. At the outset, event organizers have little influence on spectators' identification or emotional connection with the sport, but they can create unique and innovative event concepts, thereby increasing the perceived value and attracting more spectators. Our study attempts to demonstrate the important role in cre- 
ating these unique and innovative event concepts play in perceptions of value, which in turn may strengthen spectators' identification and/or emotional feelings in connection with the sport.

\section{Event Context}

The event under investigation is the International Children's Games (ICG) held in Windsor, Ontario, Canada in the summer of 2013. The ICG is a multisport event that is sanctioned by the International Olympic Committee for youth aged 12 to 15 years old. The event takes place annually, and the host community determines the sport competitions that are contested. Communities from around the world bid to host the games, and, to date, over 35,000 athletes have been involved in the games from 370 towns and 85 countries (ICG, n.d.). The 2013 ICGs involved eight sports: baseball, basketball, gymnastics, soccer, swimming, tennis, track and field, and volleyball. The 1,640 athletes represented 84 cities across 23 countries.

The ICG is a unique event in many different ways. It was the first event of this size and international rigor hosted in the city. The event acted as a springboard to build a new $\$ 78$ million aquatic complex (City of Windsor, 2011, June 13), and received a high level of local media attention. Some locals observed as though it felt as if the Olympic Games were coming town (Pearson, 2013, August 16). The event required 1,200 volunteers and 250 local team ambassadors who spoke 25 different languages. The local newspaper reported that it attracted close to 4,000 tourists into Windsor-Essex County (Windsor Star, 2013). The eight sports were each organized in a different venue within Windsor-Essex County. Spectators could watch the competitions for free.

Unlike most international events, athletes did not necessarily have to qualify to participate in the event as the cities select the teams they send to this event based on their own selection criteria. While the ICG is a competitive, international event, this implies that, the level is not necessarily high performance. The host community had a participating team in each sport, comprised of athletes from local clubs, thereby enhancing interest from people in the community (e.g., other club members, parents, and friends) to come and watch the events. Table 1 highlights the unique features of this event, as well as the characteristics that may affect perceived value.

Thus, given the context of the event under investigation, sport identity and personal affiliation of spectators may strongly vary. Some spectators may identify with a particular sport, others with a participant, yet other residents may attend merely because of the fact that the opportunity presents itself in the community. Those with higher levels of identification with the sport, or a stronger personal affiliation may be more likely to see value in the event; we predict, however, that perceptions of uniqueness may affect this relationship. By way of summary, the model to be tested in this study appears in Figure 1. 
Table 1

Unique Features and Characteristics of Perceived Value of the 2013 International Children's Games

\section{Event Characteristics}

Athletic Performance (offering)

Skill Youth, age 12 to 15, sub-elite performance, international in scope

Thrill Balanced competition to be expected

Event Atmosphere and Physical

Space

Geographic location Host city is a medium sized city; bordering a major US city. This, together with the that it is in Canada may make it an attractive destination for international visitors.

Appealing venues Swimming was organized in a new, state of the art Aquatic Centre, specifically built for this event. The other seven sports were organized in different existing community venues.

Facility features The new Aquatic Centre generated a "wow" effect; all other venues were common sport facilities, with the necessary amenities.

Theming Theming included the international dimension of the event (i.e., reaching out to the ethnically diverse community); flag posts in and around the city, and an area featuring ICG social events in a down town core plaza.

Accessibility of Venues

Transportation All venues were easily accessible

Parking There were no parking issues

Traffic congestion The event did not generate particular traffic congestion

\begin{tabular}{ll}
\hline $\begin{array}{l}\text { Relational Experiences } \\
\text { Consumer to consumer interac- } \\
\text { tions }\end{array}$ & $\begin{array}{l}\text { The international character of the event offered interesting op- } \\
\text { portunities for mingling; the ethnically diverse community was } \\
\text { actively approached to get involved with the event. }\end{array}$ \\
\hline Price Value & \multicolumn{1}{c}{$\begin{array}{l}\text { Perceived Value } \\
\text { admission fee to watch the events }\end{array}$} \\
\hline Performance Value & $\begin{array}{l}\text { Youth sport event, not necessarily of high quality, but compet- } \\
\text { ing internationally }\end{array}$ \\
\hline Emotional Value & $\begin{array}{l}\text { The international character and the community spirit may affect } \\
\text { the emotional value }\end{array}$ \\
\hline Social Value & $\begin{array}{l}\text { The international character and the community spirit may affect } \\
\text { the social value }\end{array}$ \\
\hline
\end{tabular}

Journal of Amateur Sport Volume Five, Issue Two

Snelgrove, et al., 2019 
Figure 1

\section{Hypothesized model}

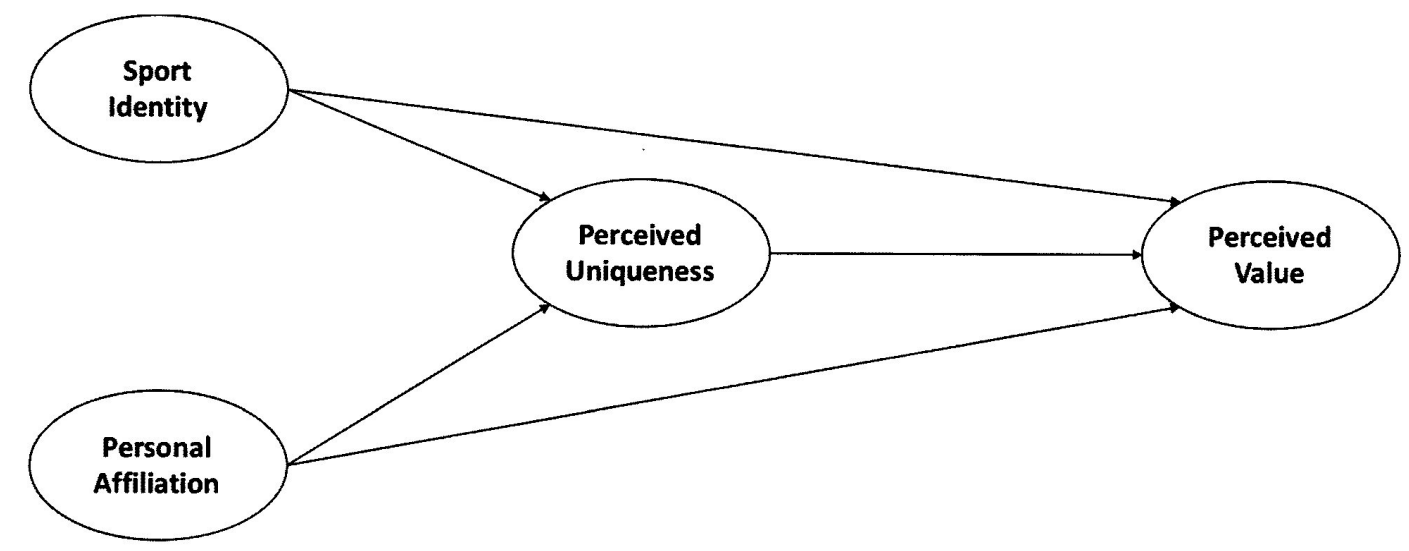

\section{Method}

\section{Data Collection}

Teams of researchers were stationed in high traffic areas within seven of the eight events venues. Tennis was excluded because there was no good area for spectators to watch the event. Researchers approached as many participants as possible and asked spectators if they would be interested in completing a survey. Interested spectators were provided a paper copy of the survey, a pencil, and an envelope with instructions to return the survey to a research booth in exchange for a small gift (i.e., logoed Frisbee). A total of 1050 questionnaires were distributed. The researchers' institutional ethics review board approved all data collection procedures.

\section{Survey Measures}

The survey was part of a larger study and included a total of 73 items. This study utilized 36 items. Sport identity was measured using three items adapted from
Shamir's (1992) measure of self-identity. This measure has been used in previous sport event research and shown to have good internal consistency and discriminant validity (Green, 2001; Snelgrove et al., 2008; Wood et al., 2010). For example, one item was "Being a sports fan is an important reflection of who I am." All items were measured on a scale from 1 to $7(1=$ Strongly Disagree and $7=$ Strongly Agree). Personal affiliation to an athlete (i.e., family or friend) was dummy coded as $1=$ yes, $0=$ no. This variable was created for this study. Perceived uniqueness was measured using an adapted version of Yoshida et al.'s (2013) scale to be appropriate for the context under study, and included items were event offering, aesthetics, access, and relationships. Yoshida's study established validity and reliability through a two-stage scale development process and relied on confirmatory factor analysis as an analytical tool. Reliability and validity were established in their study. 
Figure 2

Final model

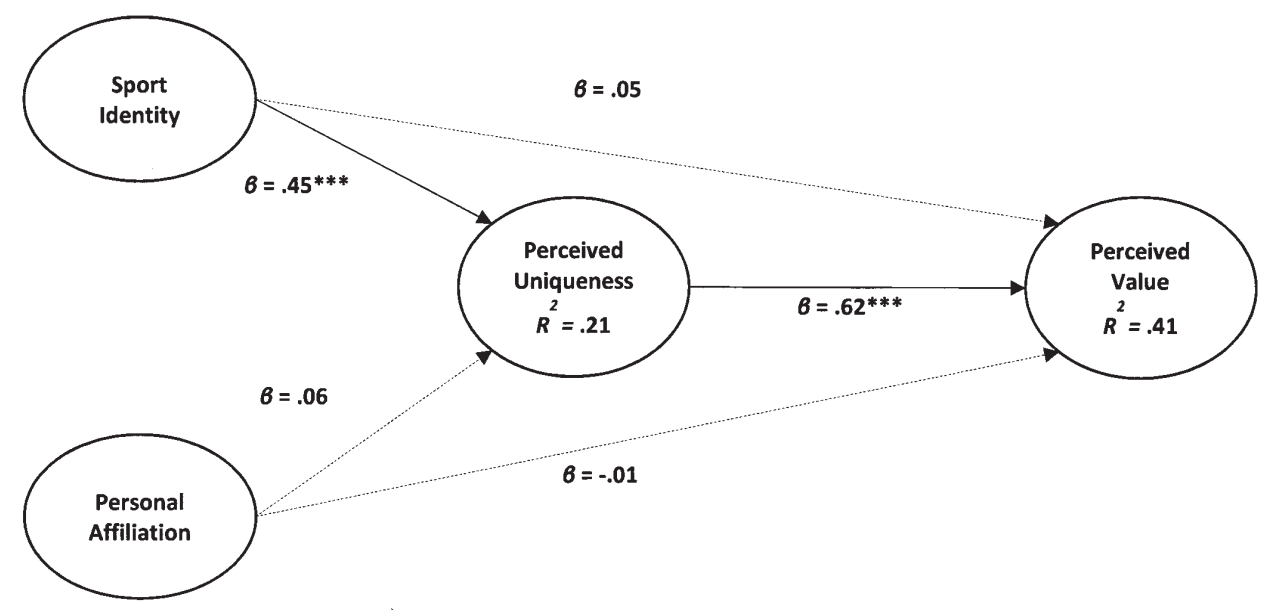

Note. $\mathrm{X} 2 / \mathrm{df}=2.16$; comparative fit index $=.982 ;$ normed fit index $=.968$; root mean square error of approximation $=.047$

The four measures of perceived value were measured by adapting Sweeney and Soutar's (2001) perceived value scale (labelled PERVAL) to a sport event context. This scale operationalizes perceived value using the dimensions of price value, performance quality, emotional value, and reputational value. For example, price value was measured with three items such as "The event is a good bargain". Performance quality was measured with three items such as, "The event is of an acceptable quality." Emotional value was measured with three items such as "Attending the event makes me feel good." Three items captured reputational or social value, such as "The event is well respected." Demographic characteristics were also collected such as age, gender, residence (local vs non-local), and disposable household income ("making ends meet" on a 5-point Likert scale, from $1=$ very difficult to $5=$ very easy).

\section{Data Analysis}

Data were first checked for normality in SPSS and no issues were found. Next, a confirmatory factor analysis (CFA) using AMOS was conducted to verify the factor structure of the measured variables. Convergent validity was assessed by comparing the average variances extracted to a cut-off point of 0.50 . Each of these AVE figures were then compared to the squared correlations of the respective factors to ensure discriminant validity was achieved (Fornell \& Larcker, 1981). Structural equation modeling was employed to assess the suitability of the hypothesized model using commonly used fit indices (Hair, Black, Banin, \& Anderson, 2018), including a test for mediation through a bootstrapping procedure in AMOS (1,000 bootstrapped samples). 


\section{Results \\ Study Participants}

In total, useable data were collected from 714 spectators out of a total of 1050 distributed during all event days (i.e., usable return rate of $68 \%$ ). Study participants ranged in age from 16-80 years, with an average age of 46 years old. Of the respondents, $60.1 \%$ of the total sample identified as female, and $73.1 \%$ were local residents. On average, the participants identified that making ends meet with their current total disposable household income was "rather easy." A total of 399 respondents (55.9\%) reported a personal affiliation to an athlete (e.g., parent, sibling, friend).

\section{Measurement Model}

The results of the confirmatory factor analysis for all constructs appear in Table 2 and indicate that all items loaded on their expected constructs. Convergent validity was established as the average variances extracted for each construct was above 0.50 , meaning more error is in the item than the latent construct (Hair et al., 2018). Additionally, composite reliability measures were all acceptable as they ranged from .808-.943, and greater than a minimum threshold of .700 (Hair et al., 2018). Last, discriminant validity was determined through a comparison of the squared correlations between constructs and the AVE value for each construct. Inspection of Table 3 indicates that all AVE values were greater than the squared correlations, a requirement for the establishment of discriminant validity (Fornell \& Larcker, 1981; Hair et al., 2018). Descriptive statistics for each construct also appear in Table 3. Study participants showed relatively high levels of identification $(M=5.56, S D=1.41)$, perception of uniqueness $(M=5.57$, $S D=1.02)$ and value $(M=5.28, S D=0.77)$ of the event.

\section{Structural Model}

Next, the model was assessed for goodness of fit. Overall, the fit indices suggested the model had a good fit to the data $\left(\chi^{2} / \mathrm{df}=2.16\right.$; CFI $=.982$; NFI $=.968$; RMSEA $=.047)$. However, not all paths in the model were significant. The significant paths were identity to perceived uniqueness, as well as perceived uniqueness to perceived value. All other paths were insignificant. More specifically, personal affiliation to an athlete was not related to perceived uniqueness or perceived value. Additionally, identity did not have a direct effect on perceived value. An inspection of the indirect effects produced through a bootstrapping procedure indicated the effect of identity on perceived value was mediated by perceived uniqueness. Thus, an indirect only effect was observed (Zhao, Lynch, \& Chen, 2010). Furthermore, a moderate to fairly high amount of variance was explained in perceived uniqueness (21\%) and perceived value (41\%) by the predictor variables (see Tables 4 and 5).

\section{Discussion}

The purpose of this study was to determine whether perceptions of value 
Table 2

Confirmatory Factor Analysis Results

\begin{tabular}{lc}
\hline Construct Item & Factor Load \\
\hline Identity & .79 \\
Being a sports fan describes me & .95 \\
Being a sports fan is an important reflection of who & \\
$\quad$ I am & .87 \\
Being a sports fan is an important part of my &
\end{tabular}

\section{Perceived Uniqueness}

The camaraderie among the event spectators is unique compared to the relationships at other events

The athletes at this event have novel skills that are different from the skills of athletes at other events

The ease of facility accessibility at this event is unique compared to other events

The unique theme of the event creates a distinctive atmosphere that is unconventional

\section{Perceived Value}

.943

.583

The event is of an acceptable quality

The event is well designed

The event is well managed $\quad .80$

Attending the event makes me feel good $\quad .81$

Attending the event gives me a sense of joy $\quad .83$

Attending the event makes me happy $\quad .85$

The event offers value for the costs to attend $\quad .75$

The event is economical to attend $\quad .72$

The event is a good bargain $\quad .66$

$\begin{array}{ll}\text { The event has a good reputation } & .70\end{array}$

The event is well respected $\quad .76$

The event is reputable $\quad .75$

Note. $\mathrm{X}^{2}(\mathrm{df})=356.56(149) ; \mathrm{X}^{2} / \mathrm{df}=2.39$; comparative fit index $=.966$; normed fit index $=.946$; root mean square error of approximation $=.055$; $\mathrm{CR}=$ composite reliability; AVE $=$ average variance extracted.

were related to a person's sport identity, their connection to an athlete, and their assessment of an event's uniqueness. Results provided support for an indirect only mediated model (Zhao et al., 2010), such that spectators who highly identified with being a sports fan perceived the event as being valuable when they also viewed the event as unique. Having a personal affiliation to an athlete was not 
Table 3

Means, Standard Deviations, and Squared correlations of Constructs

\begin{tabular}{lcccc}
\hline Construct & Mean (SD) & 1 & 2 & 3 \\
\hline 1. Identity & $5.56(1.41)$ & - & $.432^{* *}$ & $.397^{* *}$ \\
2. Uniqueness & $5.57(1.02)$ & & - & $.508^{* *}$ \\
3. Value & $5.28(.77)$ & & & - \\
\hline
\end{tabular}

${ }_{* *} p<.01$

related to perceptions of uniqueness or value. These results suggest that although highly identified sports fans view attendance as a way of celebrating their sport identities (Green, 2001; Green \& Chalip, 1998; Snelgrove et al., 2008), they may need to view the event as being unique in order to see value in the event. This finding is consistent with previous consumer behavior research, particularly in the context of retail products. For example, $\mathrm{Wu}, \mathrm{Lu}, \mathrm{Wu}$, and $\mathrm{Fu}(2012)$ found that perceived uniqueness of a handbag (i.e., the extent to which consumers viewed the product as different from other products) influenced purchase intention indirectly, through perceived value of the product. Similarly, Knight and Kim (2007) found that Japanese consumers need for uniqueness was positively related to perceived emotional value of a US apparel brand (i.e., their affective responses to the brand such as the "brand makes me feel good"). Emotional value, in turn, was positively related to purchase intention.
While the personal affiliation of spectators with performing athletes may enhance emotional attachment to the event, it did not affect the perceived uniqueness or value of the event. To reiterate, "personal affiliation" is representative of family and friends and not just someone's favorite athlete. Conversely, social connectedness among spectators is an event element upon which events can be distinguished and is a part of the uniqueness construct. Thus, the emotional attachment associated with "their" athlete performing is unique in and of itself, suggesting this emotion may be processed differently from assessments of event uniqueness or event value. However, a limitation of the measurement of personal affiliation in this study was its dichotomous nature. Future research may consider the personal affiliation as being measureable on a continuum of subjective experience rather than an objective state.

Future research should also compare different types of events in terms of 
Table 4

Standardized Direct Effects of Identity and Personal Affiliation on Perceived Uniqueness and Perceived Value

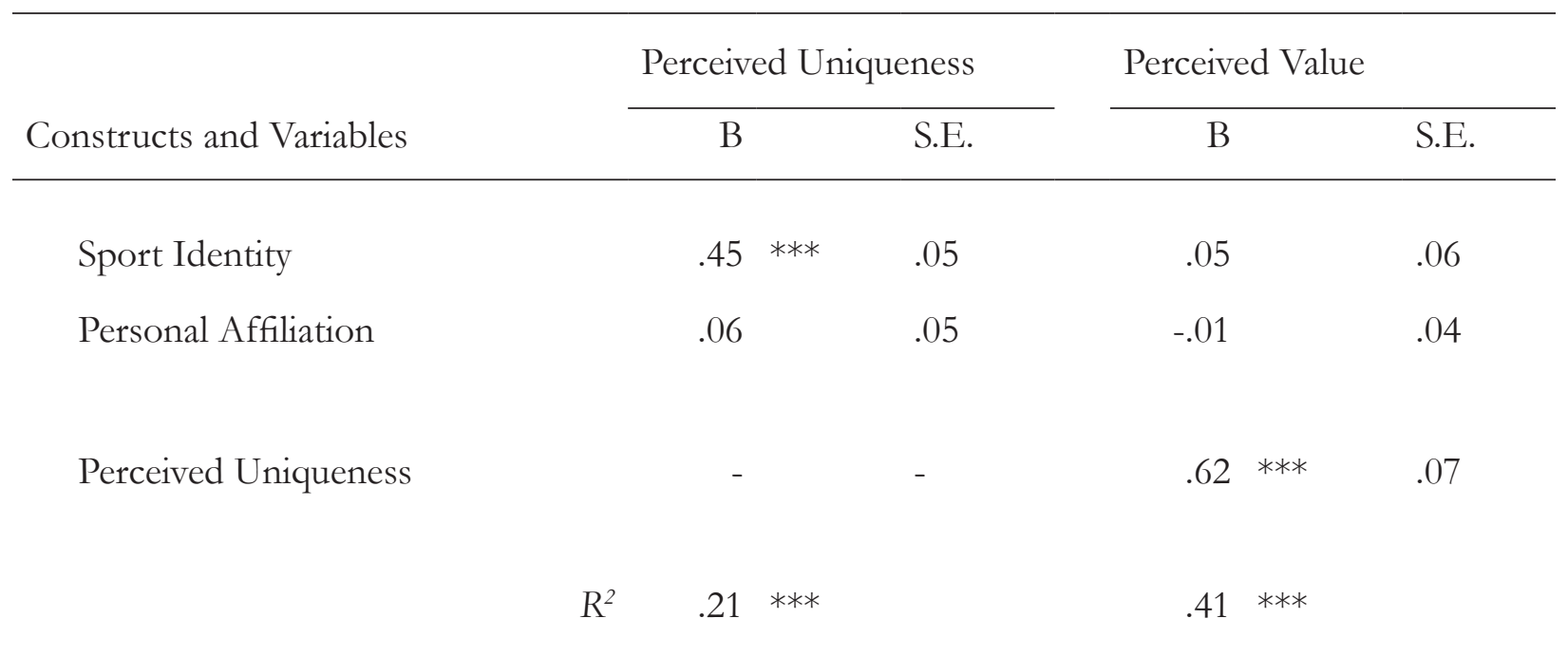

Note. ${ }^{*} \mathrm{p}<.05 * * \mathrm{p}<.01 * * * \mathrm{p}<.001$.

how they generate different perceptions of uniqueness and value. Nevertheless, the relative high average for perceived uniqueness of the event demonstrates that an event like the International Children's Games is out of the ordinary and distinct from other types of sport events. Our results confirm that high perception of uniqueness increases the perceived value of the event, thereby creating the opportunity to attract more people to come and watch the event (Yoshida et al., 2013).
Event organizers and city officials responsible for selecting and organizing sport events with a spectator focus can draw some practical implications from this study. There are several ways in which event organizers can influence unique features of an event, thereby enhancing perceived event value, and potentially attract more spectators (Yoshida et al., 2013). First, they can create opportunities to strengthen team identification, through organizing social event related events (e.g., Green, 2001), thereby also

Table 5

Standardized Indirect Effects of Identity and Personal Affiliation on Perceived Value through Perceived Uniqueness

\begin{tabular}{lll}
\hline Path & Standardized Estimates & S.E. \\
\hline Identity & $.28^{* *}$ & .05 \\
Personal affiliation & .04 & .02 \\
\hline
\end{tabular}

Note. ${ }^{*} \mathrm{p}<.05 * * \mathrm{p}<.01 * * * \mathrm{p}<.001$ 
creating opportunities for camaraderie, liminal experiences and communitas (Chalip, 2006). A focus on enhancing the sense of community among spectators is beneficial. Events can be purposefully designed to enhance this communal effect, such as the creation of social activities, a promoted spirit of friendship, theming for the overall event and particular sub-groups, and the flow of the physical setting in a way that allows for interaction (Nordvall et al., 2014). Importantly, though, social opportunities may need be perceived as novel in some way. Creating such opportunities will allow highly identified sports fans to celebrate their sport identities (e.g., Green, 2001), which will increase their perceptions of the event's value.

Second, event organizers need to pay considerable attention to the design and selection of events that have aesthetic appeal, including a unique theming. For example, in the context of this study the ICG was able to leverage the international theme of the event to create excitement and attract members from Windsor's ethnically diverse community to support athletes from various countries. This in turn, provides opportunities to create new or strengthen existing relationships (Shipway \& Jones, 2007). Deliberate theming, as was done for ICG, enhances the effect of the aesthetic element of the event throughout the city (Chalip \& McGuirty, 2004). It is important that this type of theming occurs prior to the event to generate excitement from local residents, as well as during the event when visitors and local residents are traveling throughout the city (Snelgrove \& Wood, 2010).

Third, events should be selected in concert with an availability of facilities that have an appealing aesthetic quality like for example capitalizing on the state of the art Aquatic Center in the context of the ICG. The venue itself attracted many curious local residents to the event. A city's ability to make their best facilities available to event organizers is important (Snelgrove \& Wood, 2010), but event organizers should also promote appealing (features of) venues in addition to the event itself, if the opportunity presents itself.

The limitations associated with this study should be acknowledged and considered when conducting future research on this topic. Although this study was built upon previous research on events, the inclusion of event elements was not exhaustive. Thus, future work should measure other event elements and assess their relationship with perceived value. For example, factors such as excitement or perceived social impact (positive and negative) could be considered. Data were collected at a relatively large youth sport event, thus, caution should be exercised in extrapolating the implications to smaller scale youth events without future research. Last, the data were collected in one particular city, making it unclear if local residents in other cities would respond to these events in a similar way. However, this limitation is partially reduced by the inclusion of visitors in the sample. 


\section{Conclusion}

This study reinforces the idea that purposefully selecting and designing unique events and promoting the unique attributes of the event will increase its appeal to spectators who highly identify with the sport.

\section{References}

Agha, N., \& Taks, M. (2015). A theoretical comparison of the economic impact of large and small events. International Journal of Sport Finance, 10, 103-121.

Berridge, G. (2012). Event experience: A case study of difference between the way in which organizers plan an event experience and the way in which guests receive the experience. Journal of Park and Recreation Administration, 30(3), 7-23.

Berry, L. L., Shankar, V., Parish, J. T., Cadwallader, S., \& Dotzel, T. (2006). Through service innovation: Creating new markets. Sloan Management Review, 47(2), 56-63.

Brady, M. K., \& Cronin, J. J. (2001). Some new thoughts on conceptualizing perceived service quality: A hierarchical approach. Journal of Marketing, 65(3), 34-49.

Chalip, L. (2006), "Towards social leverage of sport events", Journal of Sport \& Tourism, Vol. 11, pp. 109-127.

Chalip, L., and McGuirty, J. (2004), "Bundling sport events with the host destination", Journal of Sport \& Tourism, Vol. 9, pp. 267-282.
City of Windsor. (2011, June 13). Council Minutes. Retrieved from http:/ /www. citywindsor.ca/cityhall/City-Council-Meetings/Documents/Council_Minutes/2013/June \%2013,\%20 2011w\%20amended.pdf

Daniels, M. J., \& Norman, W. C. (2003). Estimating the economic impacts of seven regular sport tourism events. Journal of Sport Tourism, 8(4), 214-222.

Dorsch, T.E., Smith, A. L., \& McDonough, M.H. (2009). Parents perceptions of child-to-parent socialization in organized youth sport. Journal of Sport and Exercise Psychology, 31, 444-468.

Fornell, C. \& Larcker, D. F. (1981). Evaluating structural equation models with unobservable variables and measurement error. Journal of Marketing Research 18(1), 39-50.

Funk, D. C., Filo, K., Beaton, A. A., \& Pritchard, M. (2009). Measuring the motives of sport event attendance: Bridging the academic-practitioner divide to understanding behavior. Sport Marketing Quarterly, 18, 126-138.

Gibson, H. J., Kaplanidou, K., \& Kang, S. J. (2012). Small-scale event sport tourism: A case study in sustainable tourism. Sport Management Review, 15, 160-170.

Green, B. C. (2001). Leveraging subculture and identity to promote sport events. Sport Management Review, 4, 1-20.

Green, B. C., \& Chalip, L. (1998). Sport tourism as the celebration of subcul- 
ture. Annals of Tourism Research, 25, 275-291.

Hair, J. F., Black, W. C., Babin, B.J., \& Anderson, R.E. (2018). Multivariate data analysis ( ${ }^{\text {th }}$ ed.). Saddle River, NJ: Pearson Prentice Hall.

Hassay, D. N., \& Peloza, J. (2009). Building the charity brand community. Journal of Nonprofit \& Public Sector Marketing, 21, 24-55.

Henard, D. H., \& Dacin, P. A. (2010). Reputation for product innovation: Its impact on consumers. Journal of Product Innovation Management, 27(3), 321-335.

Higham, J. (1999). Commentary - sports as an avenue of tourism development: An analysis of the positive and negative impacts of sports tourism. Current Issues in Tourism 2(1), 82-90.

James, J. D., \& Ross, S. D. (2004). Comparing sport consumer motivations across multiple sports. Sport Marketing Quarterly, 13, 17-25.

Kaplanidou, K., \& Gibson, H. (2012a). Event image and traveling parents' intentions to attend youth sport events: a test of the reasoned action model. European Sport Management Quarterly, 12, 3-18.

Kaplanidou, K., \& Gibson, H. (2012b). Differences between first time and repeat spectator tourists of a youth soccer event: intentions and image approaches. Current Issues in Tourism Letters, 15, 477-487.

Kaplanidou, K., \& Vogt, C. (2007). The interrelationship between sport event and destination image and sport tourists' behaviours. Journal of Sport \& Tourism, 12(3-4), 183-206.

Kelley, S. W., \& Turley, L. W. (2001). Consumer perceptions of service quality attributes at sporting events. Journal of Business Research, 54, 161-166.

Kim, Y. K., \& Trail, G. (2010). Constraints and motivators: A new model to explain sport consumer behavior. Journal of Sport Management, 24, 190210.

Kim, Y, K., Trail, G. T., \& Magnusen, M. J. (2013). Transition from motivation to behaviour: Examining the moderating role of identification (ID) on the relationship between motives and attendance. International Journal of Sports Marketing \& Sponsorship, 1, 190211.

Ko, Y. J., Zhang, J. J., Cattani, K., \& Pastore, D. L. (2011). Assessment of event quality of major spectator sports. Managing Service Quality, 21, 304-322.

Knight, D.E., \& Kim, E.Y. (2007). Japanese consumers' need for uniqueness: Effects on brand perceptions and purchase intention. Journal of Fashion Management and Marketing, 11(2), 270-284.

Kruger, M., \& Saayman, M. (2012). Creating a memorable spectator experience at the Two Oceans marathon. Journal of Sport \& Tourism, 17, 63-77.

Kwak, D. H., \& Kang, J. H. (2009). Symbolic purchase in sport: the roles of self-image congruence and perceived quality. Management Decision, 47, 85-99. Kwon, H. H., Trail, G., \& James, J. D. (2007). The mediating role of per- 
ceived value: Team identification and purchase intention of team-licensed apparel. Journal of Sport Management, 21, 540-554.

Lee, J., Lee, J., \& Feick, L. (2001). The impact of switching costs on the customer satisfaction-loyalty link: Mobile phone service in France. Journal of Services Marketing, 15, 35-48.

Mahony, D. F., Nakazawa, M., Funk, D. C., James, J. D., \& Gladden, J. M. (2002). Motivational factors influencing the behaviour of J. League Spectators. Sport Management Review, 5, 1-24.

McAlexander, J. H., Schouten, J. W., \& Koenig, H. F. (2002). Building brand community. Journal of Marketing, 66(1), $38-54$.

Müller, M. (2015). What makes an event a mega-event? Definitions and sizes. Leisure Studies, 34(6), 627-642.

Mullin, B. J., Hardy, S., \& Sutton, W. A. (2014). Sport marketing (4th Edition). Champaign, IL: Human Kinetics.

Muniz, A. M., \& O'Guinn, T. C. (2001). Brand community. Journal of Consumer Research, 27, 412-432.

Nordvall, A., Pettersson, R., Svensson, B., \& Brown, S. (2014). Designing events for social interaction. Event Management, 18, 127-140.

O’Brien, D., \& Chalip, L. (2008). Sport events and strategic leveraging: Pushing towards the triple bottom line. In A. Woodside and D. Martin (Eds.), Tourism management: Analysis, behaviour and strategy (pp. 318-38). Oxfordshire, UK: CABI.
Oliver, R. L. (1999). Whence consumer loyalty? Journal of Marketing, 63, 33-44. Pearson, C. (2013, August 16). What a splash: Windsor's golden moment. Windsor Star. Retrieved from https:/ / blogs.windsorstar.com/2013/08/16/ what-a-splash-windsors-golden-moment/

Pritchard, M. P., Funk, D. C., \& Alexandris, K. (2009). Barriers to repeat patronage: The impact of spectator constraints. European Journal of Marketing, 43, 169-187.

Pullman, M. E., \& Gross, M. A. (2004). Ability of experience design elements to elicit emotions and loyalty behaviors. Decision Sciences, 35, 551-578.

Rui, B., Correia, A., Santos, T., Ross, S., \& Yoshida, M. (2017). Service quality and value perceptions of the 2014 FIFA World Cup in Brazil. Event Management, 21, 201-216.

Shamir, B. (1992). Some correlates of leisure identity salience: Three explanatory studies. Journal of Leisure Research, 24, 301-323.

Shipway, R., \& Jones, I. (2007). Running away for home: Understanding visitor experiences and behaviour at sport tourism events. International Journal of Tourism Research, 9, 373-383.

Shonk, D. J., \& Chelladurai, P. (2008). Service quality, satisfaction, and intent to return in event sport tourism. Journal of Sport Management, 22, 587-602. Snelgrove, R., Taks, M., Chalip, L., \& Green, B. C. (2008). How visitors and locals at a sport event differ in mo- 
tives and identity. Journal of Sport \& Tourism, 13, $165-180$.

Snelgrove, R., \& Wood, L. (2010). Attracting and leveraging visitors at a charity cycling event. Journal of Sport \& Tourism, 15, 269-285.

Sweeney, J. C., \& Soutar, G. N. (2001). Consumer perceived value: The development of a multiple item scale. Journal of Retailing, 77, 203-220.

Taks, M. (2013). Social sustainability of non-mega sport events in a global world. European Journal for Sport and Society, 10, 121-141.

Taks, M., Chalip, L., \& Green, B. C. (2015). Impacts and strategic outcomes from non-mega sport events for local communities. European Sport Management Quarterly, 15(1), 1-6.

Trail, G. T., Fink, J. S., \& Anderson, D. F. (2013). Sport spectator consumption behavior. Sport Marketing Quarterly, 12, 8-17.

Trail, G. T., \& James, J. D. (2001). The motivation scale for sport consumption: Assessment of the scale's psychometric properties. Journal of Sport Behavior, 24, 108-127.

Trail, G. T., Robinson, M. J., Dick, R. J., \& Gillentine, A. J. (2003). Motives and points of attachment: Fans versus spectators in intercollegiate athletics. Sport Marketing Quarterly, 12, 217-227.

Wakefield, K. L., \& Blodgett, J. G. (1996). The effect of the servicescape on customers' behavioral intentions in leisure service settings. Journal of Services Marketing, 10, 45-61.
Walo, M., Bull, A., \& Breen, H. (1996). Achieving economic benefits at local events: A case study of a local sports event. Festival Management and Event Tourism, 4(3-4), 95-106.

Wann, D. L. (1995). Preliminary validation of the sport fan motivation scale. Journal of Sport and Social Issues, 19, 377-396.

Wiersma, L. D., \& Fifer, A. M. (2008). 'The schedule has been tough but we think it's worth it': The joys, challenges, and recommendations of youth sport parents. Journal of Leisure Research, 40, 505-530.

Wigfield, D., \& Chard., C. (2018). Understanding brand associations of preferred minor hockey tournaments from the parents' perspective. Event Management, 22, 183-198.

Windsor Star (2013), "Star editorial: in the wake of the Games", August 20, available at: http://windsorstar.com/ opinion/editorials/star-editorial-inthe-wake-of-the games/ (accessed 12 September 2013).

Wood, L., Snelgrove, R., \& Danylchuk, K. (2010). Segmenting volunteer fundraisers at a charity sport event. Journal of Nonprofit \& Public Sector Marketing, 22(1), 38-54.

Wu, W.Y., Lu, H.Y., Wu, Y.Y., \& Fu, C.S. (2012). The effects of product scarcity and consumers' need for uniqueness on purchase intention. International Journal of Consumer Studies, 36(3). 263-274.

Yoshida, M., \& James, J. D. (2010). Customer satisfaction with game and 
service experiences: Antecedents and consequences. Journal of Sport Management, 24, 338-361.

Yoshida, M., \& James, J. D. (2011). Service quality at sporting events: Is aesthetic quality a missing dimension? Sport Management Review, 14, 13-24. Yoshida, M., James, J. D., \& Cronin, J. J. (2013). Sport event innovativeness: Conceptualization, measurement, and its impact on consumer behavior. Sport Management Review, 16, 68-84.
Zeithamal, V. A. (1988). Consumer perceptions of price, quality, and value: A means-end model and synthesis of evidence. Journal of Marketing, 52(3), 2-22.

Zhao, X., Lynch, J. G., \& Chen, Q. (2010). Reconsidering Baron and Kenny: Myths and truths about mediation analysis. Journal of Consumer Research, 37, 197-206. 